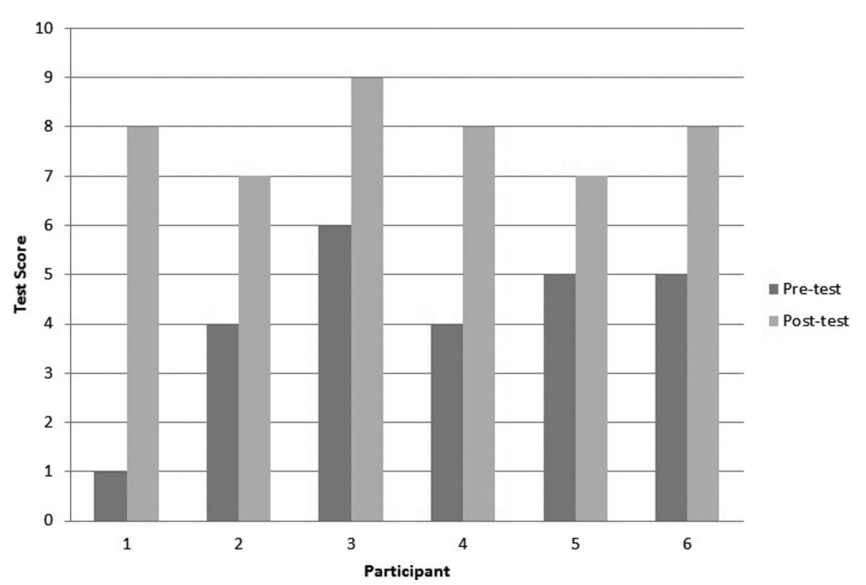

Abstract M25 Figure 1

$\left(\mathrm{PaO}_{2}=84.9 \mathrm{mmHg}\right)$, caused mild hypercapnia $\left(\mathrm{PaCO}_{2}=49.6\right.$ $\mathrm{mmHg}$ ) and the blood $\mathrm{pH}$ was normal $(\mathrm{pH}=7.37) .100 \%$ oxygen enabled better arterial oxygenation $\left(\mathrm{PaO}_{2}=129.3 \mathrm{mmHg}\right)$ but caused severe hypercapnia $\left(\mathrm{PaCO}_{2}=100.9 \mathrm{mmHg}\right)$ and acidosis $(\mathrm{pH}=6.98)$. Preclinical medical students were randomly allocated to simulation or lecture-based learning (the study has a crossover design) and were taught the correct use of oxygen administration. A greater proportion of students rated they had an excellent understanding of the key learning points after simulation (100\%) compared to the lecture- based learning $(33 \%)$ and it was sufficient to significantly improve test scores $(p=0.0135)$. Simulation could be used to educate future health professionals in using $28 \%$ oxygen to reduce the risk of hypercapnic respiratory acidosis in AECOPD.

\section{M26 TWEETING IS TEACHING - \#RESPED: FREE, OPEN- ACCESS TWITTER EDUCATIONAL RESOURCE FOR TRAINEES AND SPECIALISTS IN RESPIRATORY MEDICINE}

${ }^{1}$ RW Lee, ${ }^{2} \mathrm{~L}$ Smith, ${ }^{2} \mathrm{~T}$ Hillman. 'Division of Asthma, Allergy and Lung Biology, Guy's Hospital, King's Health Partners, London, UK; ${ }^{2}$ University College London Hospitals NHS Foundation Trust, London, UK

\subsection{6/thoraxjnl-2015-207770.453}

Introduction Social media use in medical education is expanding rapidly, bringing with it a novel means of learner engagement, feedback, collaboration and professional development. ${ }^{1}$ A growing body of respiratory specialists and trainees are now engaging in such activities via Twitter. ${ }^{2}$ We describe one of the commonest dedicated Respiratory 'Hashtags' (“\#RespEd”) where content related to evidence-based medicine (EBM), e-learning and collaboration is curated.

Methods "\#RespEd" tweets were reviewed for usage statistics since 01/01/2013 using www. Symplur.com with more detailed review of monthly analytics since 01/04/2014. All "\#RespEd" tweets were downloaded from Twitter and Symplur. Transcripts were reviewed for content using Microsoft Excel. A review of related hastags identified through Symplur was conducted to assess reach across Respiratory hashtags in a similar timeframe. Results The "\#RespEd hashtag" was first used in January 2013. Since this time, Symplur identified 1,099 participants and 5,973 tweets. Audience 'reach' was recorded as 7,384,722 impressions. A steady increase in users has evolved in the last 18 months with clear peaks in activity around the BTS Summer and Winter meetings. Participants included a wide range of professionals including doctors, nursing staff, pharmacists, physiotherapists, patients and representatives of societies and mainstream respiratory journals. Users were from numerous countries. Common content included evidence-based medicine (e.g. recently published articles), e-learning resources and 'live-tweets' from training days, which were usually picture tweets of lecturers slides. Other established respiratory hashtags included (participants): \#ATS2015 (2,812), \#ERS2014 (2,179), \#Pulmcc (1,927), \#BTSWinter (487).

Conclusions Twitter represents an untapped respiratory educational resource, which is truly multi-disciplinary and breaks boundaries between professional groups. The BTS conferences have provided a clear platform to broaden this resource. There is an opportunity to reach out to trainees and others seeking continuing professional development and provide both reliable resources and a 'place' to foster debate and discourse on topical respiratory themes.

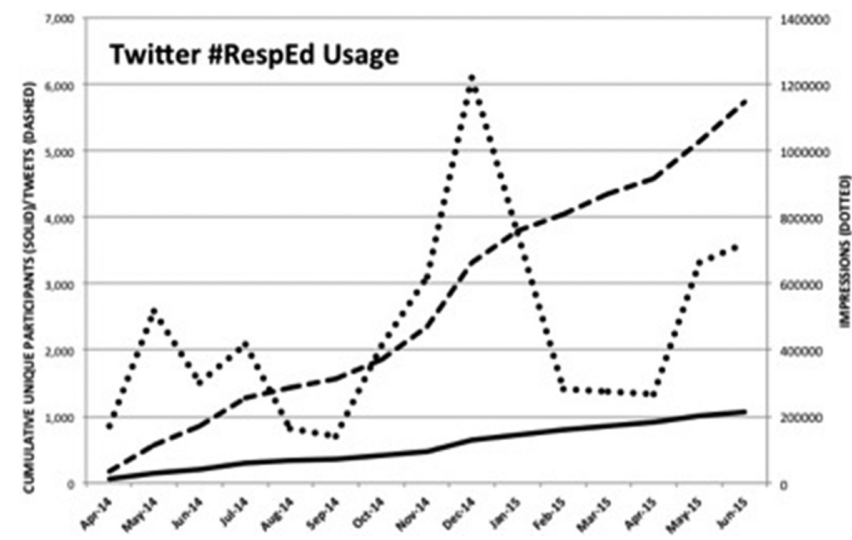

Abstract M26 Figure 1

\section{REFERENCES}

1 Cheston CC, Flickinger TE, Chisolm MS, et al. Social media use in medical education: a systematic review. Acad Med. 2013;88(6):893-901

2 Chalmers JD, Greening NJ, Jose RJ, et al. Review of the British Thoracic Society Winter Meeting 2013. Thorax 2014;69:378-382

\section{M27 WHEEZES, COUGHS AND SPLUTTERS: HOW DO PAEDIATRIC TRAINEES MANAGE THEM?}

${ }^{1} \mathrm{M}$ Ramphul, ' $\amalg$ Thanikkel, ${ }^{2} \mathrm{R}$ Ross Russell. ${ }^{1}$ East of England Deanery, Cambridge, UK; ${ }^{2}$ Cambridge University Hospitals NHS Foundation Trust, Cambridge, UK

10.1136/thoraxjnl-2015-207770.454

Introduction and objectives Wheezy pre-school children frequently present to paediatric departments. There is a wide variation in how paediatric trainees investigate and manage these children, which can be associated with unnecessary costs to the NHS. Our aim was to assess this diversity in management options initiated by paediatric trainees.

Methods Web-based survey on how paediatric trainees approach scenarios of wheezy pre-school children. Trainees across the UK were asked to fill in a questionnaire consisting of four case scenarios involving wheezy children under the age of 5 .

Results 194 trainees responded to the survey. There was a good representation amongst different training grades across UK deaneries. In the bronchiolitis scenario, $13 \%$ requested blood tests or 